\title{
Survey of Fungal Diversity in Silages Supplied to Dairy Cattle in Belgium Over a Two-Year Period
}

Tangni E. K., Wambacq E., Bastiaanse H., Haesaert G., Pussemier L., De Poorter J., Foucart G. and Van Hove F.

J Anim Sci Adv 2017, 7(1): 1861-1873

DOI: $10.5455 /$ jasa.196912310400000110

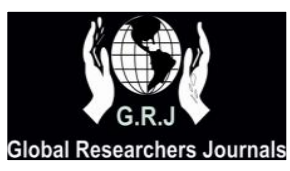




\title{
Survey of Fungal Diversity in Silages Supplied to
}

\section{Dairy Cattle in Belgium Over a Two-Year Period}

\author{
${ }^{* 1}$ Tangni E. K., ${ }^{2}$ Wambacq E., ${ }^{3}$ Bastiaanse H., ${ }^{2}$ Haesaert G., ${ }^{1}$ Pussemier L., ${ }^{4}$ De Poorter J., \\ ${ }^{4}$ Foucart G. and ${ }^{3}$ Van Hove F. \\ ${ }^{1}$ Operational Directorate of Chemical Safety of the Food Chain, Service of Toxins and Natural Components, Veterinary and \\ Agrochemical Research Centre (CODA-CERVA), Leuvensesteenweg 17, 3080 Tervuren, Belgium. \\ ${ }^{2}$ University College Ghent, Faculty of Biosciences and Landscape Architecture, Schoonmeersstraat 52, 9000 Gent, Belgium. \\ ${ }^{3}$ Mycothèque de l'UCL (BCCM/MUCL), Earth and Life Institute (ELI) - Applied Microbiology (ELIM), Université catholique de \\ Louvain (UCL), Croix du Sud 2 bte L7.05.06, B-1348 Louvain-la-Neuve, Belgium. \\ ${ }^{4}$ Centre Indépendant de Promotion fourragère (C.I.P.F. asbl), Unité d'écologie des prairies et grandes cultures, Université catholique \\ de Louvain (UCL), Croix du Sud, 2 bte L7.05.11, B-1348 Louvain-la-Neuve. Belgium.
}

\begin{abstract}
The fungal diversity in silages for dairy cattle feeding has been assessed by purification and identification of 966 isolates collected in silages during the two 2006 and 2007 winter storage/feed-out periods from farms localized in various geographic regions in Belgium. The relevant fungal species in silos were $P$. paneum and $P$. roqueforti (18.2\% and $14.5 \%$ of total isolates, respectively). The proportion between the two species varied significantly from 2006 to 2007 ( $\mathrm{P}<0.05)$ depending on the type of forage crop. The prevalence of $P$. paneum in Belgium compared to results in other countries is of major importance due to the mycotoxigenic capacity of this species. Information on numerous aspects of silage making process and silo management showed that neither the crop rotation, the date and weather at harvest, the use of additives, the feeding rate, the type and dimension of silo, the covering used nor the forage chopping length at ensiling could be significantly correlated to the fungal species composition isolated in farm silages. There were also no significant relationships between the chemo-fermentative parameters tested (dry matter, $\mathrm{pH}, \mathrm{NH} 3$ content, concentration of lactic, acetic and butyric acids) and the fungal species composition in silages. The prevalent fungi were tolerant of the wide ranges of conditions found in the farm silages with year-to-year variations.
\end{abstract}

Keywords: Quality, mycotoxins, silages, fungal diversity, prevalence, silo management.

${ }^{*}$ Corresponding author: Operational Directorate of Chemical Safety of the Food Chain, Service of Toxins and Natural Components, Veterinary and Agrochemical Research Centre (CODA-CERVA), Leuvensesteenweg 17, 3080 Tervuren, Belgium.

Received on: 22 Oct 2016

Revised on: 02 Nov 2016

Accepted on: 28 Jan 2017

Online Published on: 31 Jan 2017

1861 J. Anim. Sci. Adv., 2017, 7(1): 1861-1873 


\section{SURVEY OF FUNGAL DIVERSITY IN SILAGES SUPPLIED TO ...}

\section{Introduction}

Mould species that have been regularly isolated from silage belong to the genera Alternaria, Aspergillus, Byssochlamys, Fusarium, Geotrichum, Monascus, Mucor, Paecilomyces, Penicillium, and Trichoderma (Scudamore and Livesey, 1998; O'Brien et al., 2008, Tangni et al., 2013a, Wambacq et al., 2016). Fungal contaminations not only cause a reduction in feed value, palatability and consequently intake of the silage (DiCostanzo et al., 1995), but may also have a negative effect on human and animal health, livestock productivity and the cost of regulatory programs directed towards food safety. Inhalation of heavy concentrations of certain airborne mould conidia, such as spores of Aspergillus fumigatus, can affect the respiratory system and lead to allergenic reactions for animal and human exposed to the contaminated silage (Bui et al., 1994). Moreover, moulds may produce mycotoxins, which may have deleterious effects in synergistic, additive or antagonistic ways on animals consuming the contaminated product (Auerbach et al., 1998; D’Mello et al., 1999).

Most mycotoxins of concern are produced by three genera of fungi, namely Aspergillus, Penicillium and Fusarium. Their occurrence represents a dual hazard for dairy cattle and farm workers. Aspergillus fumigatus produces a number of toxic metabolites such as clavine alkaloids (fumigaclavine $\mathrm{A}$ and $\mathrm{C}$ ) and several tremorgenic compounds which may diffuse into the silage. Associated symptoms in dairy cattle are severe diarrhea, irritability and loss of appetite (Tangni et al., 2013a). Subclinical exposure to mycotoxins may be much more frequent, resulting in nonspecific symptoms and affecting animal productivity. A certain degree of contamination seems to be unavoidable under current agricultural and silage making practices (Cheli et al., 2013).

A high diversity of Penicillium species has been isolated from silages. Penicillium roqueforti, a species which is acid tolerant and can grow at low levels of oxygen and high levels of $\mathrm{CO}_{2}$, has been detected as the predominant species in different types of silages (Nout et al., 1993; Auerbach et al., 1998). P. roqueforti s.s. moulds probably included $P$. roqueforti isolates as well as $P$. paneum isolates before the discovery of multiple species within the $P$. roqueforti group. In addition, Fusarium species including $F$. graminearum and $F$. culmorum infest plants in the field and can survive during ensiling (Wambacq et al., 2016). Knowledge of fungal populations in farm silages in Belgium is sparse, notwithstanding the fact that mould spoilage of silage is quite common and can adversely affect animal health and productivity. The present study focused at determining the fungal diversity on grass, maize and sugar beet silages belonging to various cropping systems in farms from various geographic regions in Belgium. It aimed also at determining whether the ensiling practices could be correlated with the contaminating fungal species.

\section{Materials and Methods}

\section{Sample Collection and Handling}

During 2006 and 2007, sampling was performed in dairy farms belonging to a wide range of agricultural practices and different farm management systems from various geographic regions in Belgium. A total of 134 different silos were sampled (Table 1).

Whole crop maize $(48.5 \%)$, pre-wilted grass $(35.1 \%)$ and sugar beet pulp $(9.7 \%)$ were mainly studied, while corn cob mix (3\%) and other silages (4.2\%; e.g. grass - maize mixtures, draff) were of minor importance. Mature silages were sampled and all the silos visited were characterised by visibly mouldy parts on the cutting face, indicating the absence of adequate silage preservation and fermentation conditions throughout the silo. From each silo, mouldy and non-mouldy samples of $1.5-$ $2 \mathrm{~kg}$ were collected from the top of the silo (just below the cover plastic) as well as samples from a non-visibly infected part and from different mouldy parts of the cutting face. 
TANGNI ET AL.

Table 1: Type and number of examined silos.

\begin{tabular}{lccc}
\hline Silo Type & $\mathbf{2 0 0 6}$ & $\mathbf{2 0 0 7}$ & Total \\
\hline Maize & 30 & 35 & 65 \\
Grass & 26 & 21 & 47 \\
Sugar beet pulp & 5 & 8 & 13 \\
Corn Cob Mix & 1 & 3 & 4 \\
Maize - grass & 1 & 0 & 1 \\
Maize - pulp & 1 & 0 & 1 \\
Grass - luzern - draff & 1 & 0 & 1 \\
Draff & 0 & 1 & 1 \\
Whole Plant Silage wheat & 0 & 1 & 1 \\
Total & $\mathbf{6 5}$ & $\mathbf{6 9}$ & $\mathbf{1 3 4}$ \\
\hline
\end{tabular}

Mouldy parts were determined visually based on different colour, odour and texture. For each sample, $100 \mathrm{~g}$ were taken for fungal isolation and identification, $300 \mathrm{~g}$ for the determination of the $\mathrm{pH}$ and $\mathrm{NH} 3 / \mathrm{N}$-fraction, $300 \mathrm{~g}$ for the detection of mycotoxins, $600 \mathrm{~g}$ for the dry matter (DM) determination and $250 \mathrm{~g}$ for analysing the acetic acid $(\mathrm{AcOH})$, butyric acid (BA) and lactic acid (LA) content of silages. Samples for fermentative parameters and fungal isolation were placed in sterile bags, sealed and transferred immediately to the laboratory. Samples for mould isolation were kept at $4{ }^{\circ} \mathrm{C}$ for a maximum duration of 48 hours; the other samples were stored in the freezer at -20 ${ }^{\circ} \mathrm{C}$ until analyzed.

\section{Fungal Isolation and Identification}

The direct plating method was used to isolate moulds. Contaminated silage fragments were transferred aseptically to the surface of Potato Dextrose Agar (PDA) medium in Petri dishes. Depending on the size, two or three subsamples of silo material samples were placed at equidistant points of 2 Petri dishes. Plates were incubated for between 2 and 14 days at $25{ }^{\circ} \mathrm{C}$ depending on the growth rate of the fungi isolated. Fungal isolates were purified by sub-culture on appropriate media for identification and stored at ambient temperature for later identification. Trichoderma were transferred to Malt extract agar (MEA), while Fusarium species were placed on "synthetischer nährstoffärmer agar" (SNA). All other fungi were transferred to fresh PDA. Fungi were identified to genera or species level by their macro- and micromorphology features using appropriate identification keys (Samson et al., 2002).
To validate the morphological identification of Penicillium species, the deoxyribonucleic acid (DNA) sequence from the ribosomal internal transcribed spacers (ITS) and the partial betatubulin gene were sequenced for Penicillium monoand bi-verticillate, and Penicillium ter-verticillate respectively. For Fusarium species, partial sequences of the elongation factor (EF) were amplified and sequenced and Trichoderma species were confirmed by sequencing ITS region. All sequence data were aligned and edited in Sequencher 3.0 (Gene-Codes, Ann Arbor, MI, USA) and were compared to the GenBank database (http://www.ncbi.nlm.nih.gov/) with the BLAST-N algorithm and the closest match was recorded $(\geq$ $98 \%$ sequence identity in all cases).

Fungal isolates were grown in $20 \mathrm{ml}$ of malt extract broth and shaken at $100 \mathrm{rpm}$ at $25{ }^{\circ} \mathrm{C}$ for 7 days. Mycelia were harvested by filtering and centrifugation of the culture at $3500 \mathrm{rpm}$ for 10 minutes. After harvest, fungal mycelia were lyophilized. DNA was extracted with the DNeasy Plant Minikit (QUIAGEN, Valencia, California). Then, DNA was subjected to the polymerase chain reaction (PCR) in $50 \mu \mathrm{l}$ reactions with $10 \mu \mathrm{l}$ of sample DNA, and a final concentration of $0.2 \mu \mathrm{M}$ of each primer, $0.2 \mu \mathrm{M}$ dNTP mixture, 1x PCR buffer $(100 \mu \mathrm{M} \mathrm{KCl}$ and $20 \mu \mathrm{M}$ Tris $\mathrm{HCl}), 1.5 \mu \mathrm{M}$ $\mathrm{MgCl}_{2}$ and $2.5 \mathrm{U} / \mu \mathrm{l}$ of Taq polymerase. All reactions were carried out in a PTC-200 thermocycler (MJ Research, Waltham, Massachussets, USA) and an Eppendorf Mastercycler (Eppendorf, Hamburg, Germany). The PCR and sequencing primers used were ITS1, ITS4 and NS7 for the ITS region, $\mathrm{Bt} 2 \mathrm{a}$ and $\mathrm{Bt} 2 \mathrm{~b}$ for the Beta-tubulin, and the EF1T and EF2T for Elongation Factor (Table 2). The PCR amplification 


\section{SURVEY OF FUNGAL DIVERSITY IN SILAGES SUPPLIED TO ...}

conditions were: for ITS (i) $94{ }^{\circ} \mathrm{C}$ for $3 \mathrm{~min}, 40$ cycles of (ii) $94{ }^{\circ} \mathrm{C}$ for $1.30 \mathrm{~min}$, (iii) $55^{\circ} \mathrm{C}$ for 1.30 min, (iv) $72{ }^{\circ} \mathrm{C}$ for 4 min and a final polymerization step of (v) $72{ }^{\circ} \mathrm{c}$ for $10 \mathrm{~min}$. The amplification conditions for Beta-tubulin partial sequence were: (i) $94{ }^{\circ} \mathrm{C}$ for $3 \mathrm{~min}$, followed by 40 cycles of (ii) 94
${ }^{\circ} \mathrm{C}$ for $1 \mathrm{~min}$, (iii) $56{ }^{\circ} \mathrm{C}$ for $1.30 \mathrm{~min}$, (iv) $72{ }^{\circ} \mathrm{C}$ for $2 \mathrm{~min}$ and a final polymerization step of (v) $72{ }^{\circ} \mathrm{C}$ for $10 \mathrm{~min}$. For $\mathrm{EF}$, the amplification conditions were: (i) $92{ }^{\circ} \mathrm{C}$ for $5 \mathrm{~min}, 40$ cycles of (ii) $92{ }^{\circ} \mathrm{C}$ for $1 \mathrm{~min}$, (iii) $52{ }^{\circ} \mathrm{C}$ for $1.30 \mathrm{~min}$, (iv) $72{ }^{\circ} \mathrm{C}$ for $4 \mathrm{~min}$.

Table 2: Sequences of the primers used for the molecular identifications of fungal species isolated from silages.

\begin{tabular}{lcc}
\hline Gene & Primers & Sequences \\
\hline ITS & ITS1 & TCC GTA GGT GAA CCT GCG G \\
& ITS4 & TCC TCC GCT TAT TGA TAT GC \\
Beta-tubulin & NS7 & GAG GCA ATA ACA GGT CTG TGA TGC \\
& Bt2a & GGT AAC CAA ATC GGT GCT GCT TTC \\
Elongation factor & BT2b & ACC CTC AGT GTA GTG ACC CTT GGC \\
& EF1T & ATG GGT AAG GA5_(A/G) GAC AAG AC \\
& EF2T & GGA (G/A) GT ACC AGT (G/C)AT CAT GTT \\
\hline
\end{tabular}

PCR products were cleaned up prior to DNA sequencing with the QIAquick PCR purification Kit (QUIAGEN). Sequencing reactions were performed with the Big Dye terminators sequencing V1.1 kit (Applied Biosystems, Paolo Alto California, USA) according to the manufacturer's instructions. Sequence analysis was performed on a 3100 Genetic analyser (Applied Biosystems).

\section{Chemical Analysis of Silage Samples}

Prior to analyses, samples were thawed and homogenized. The analyses were performed on water based extracts. Therefore $100 \mathrm{~g}$ fresh material was diluted in demineralised water during 24 hours at $15{ }^{\circ} \mathrm{C}$ and filtrated. Following analyses were performed: $\mathrm{pH}$ on the demineralised water extracts, NH3 by steam distillation, lactic acid (LA), butyric acid (BA) and acetic acid (AA) contents by HPLC as described by Ohmomo et al., (1993). From the non-contaminated zone, the dry matter content was measured by drying $600 \mathrm{~g}$ fresh material at $60{ }^{\circ} \mathrm{C}$ to constant weight.

\section{Ensiling Practices and Characteristics of Forage Crops on Farms}

A detailed questionnaire was completed and contained information about numerous aspects of harvesting of the forage crop (crop rotation, preceding crop, harvest date, weather at harvest) and silo management practices (additive applied, age of the silo (weeks), feeding rate ( $\mathrm{cm} /$ day), type of silo, height, length of the silo, number of plastic film layers, weight use on the plastic film layers, chopping length). Additional observations on silage storage practices such as the beginning of the silo contamination by moulds after the opening of the silo (number of weeks), the anomalies in the animal husbandry (health troubles, diminution of the feed intake or the milk production) were recorded in situ.

\section{Statistical Analysis}

Dependence of fungal species distribution in categorical data was tested using the Chi square test at a level of $\mathrm{P}<0.05$. The occurrence of fungi in relation to the silage management practices has been analysed using the multivariate analysis CCA. Management practices were used as explanatory variables to predict the fungal biodiversity observed in farm silages. The DCA indicated that unimodal method of ordination was the most appropriate method to analyse our dataset: the longest gradient was larger than 4 standard deviation units (5.5) of species turnover. Use of the linear method would not be appropriate, as the data are too heterogeneous and too many species deviate from the assumed model of linear response (Leps and Smilauer, 1999). Therefore, CCA was chosen as the most suitable method to analyse the data. A Monte Carlo permutation test (reduced model because of missing data, 418 permutations) showed that differentiation of the species according to the first canonical axis was not statistically significant (> 0.05). It indicates that the variation in the species dataset is independent of the silo management 
practices. For these reasons, species data set was not further analysed.

\section{Results} silos visited throughout the whole sampling period. Based on the external appearance of the mouldy hot spots, 1 to 3 visually different colonies (average = 1.3) were removed from the cutting face of the silos. Fungal isolations were initiated on 654 colonies (306 and 348 colonies for 2006 and 2007, respectively) sampled from different parts of the farm silos, resulting in 966 fungal strains. Single pure fungal cultures were isolated from 443 samples by direct plating method of small fragments of mouldy silage on Petri dishes. For the other samples, 2 to 4 different fungal isolates with different morphological traits were observed on the same mouldy part of silage. In most cases, all the co-existing strains sampled could be isolated and identified, except when Mucoraceous moulds were the predominant fungi in the silage.

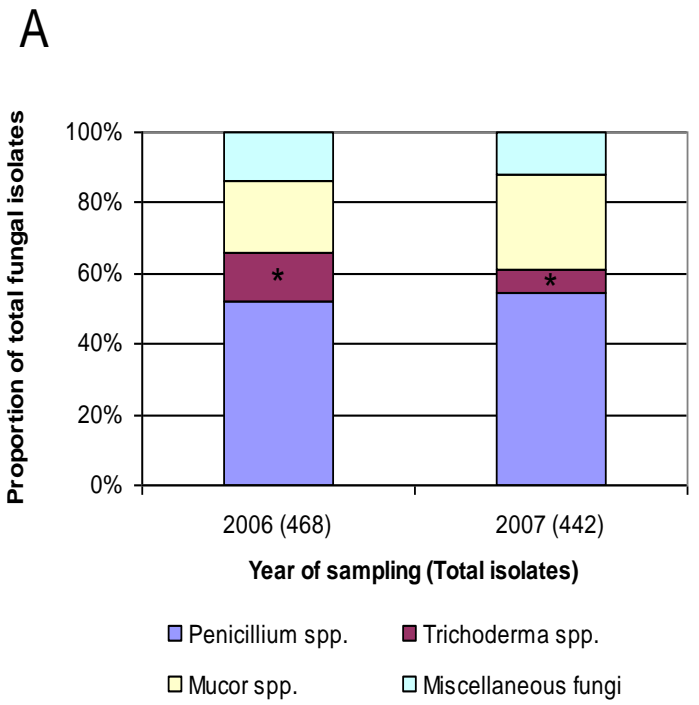

Visible fungal development was observed in all

By examination of silages sampled from January to July in 2006 and 2007 (Table 3), 37 fungal species belonging to 13 genera were identified, and 1 to 10 species were isolated from each silo throughout the sampling periods (mean = 4.6, standard deviation = 2.3). Penicillium, Trichoderma and Mucor were the most prevalent genera on the isolation media used (Figure 1), with a lower incidence of Trichoderma during the second year of sampling $(\mathrm{P}<0.05)$. Other miscellaneous fungal taxa were isolated sporadically and were identified as Alternaria alternata, Aspergillus niger, A. oryzae, A. tubingensis, Byssochlamys nivea, Fusarium equiseti, $F$. verticillioides, $F$. oxysporum, F. redolens, Monascus ruber, Monilia crassa, Paecilomyces variotii, Verticillium lamellicola and $V$. lecanii. Nevertheless, species frequencies recorded in silages might be biased by the fact that in some cases, samples plated on PDA quickly became overgrown by mucoraceous moulds before colonies of other species could be isolated successfully.

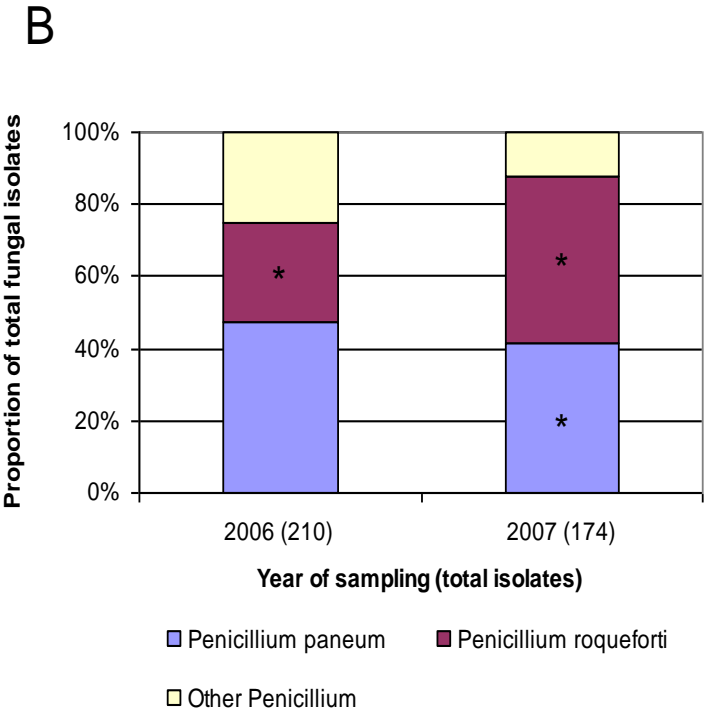

Fig. 1: Frequency of isolated fungal species in Belgian farm silages from January to July 2006 and 2007. Dependence of fungal species distribution in categorical data was tested using the Chi square test at a level of $\mathrm{P}<0.05$. Asterisks over bars indicate major contributor categories in rejecting the null hypothesis according to the residuals chi square $>2.00$.

The relevant fungal species in silos, $P$. paneum (18.2\% of total isolates) and $P$. roqueforti (14.5\% of total isolates) during the first and the second year of sampling were the most predominant ones.
Nevertheless, the proportion between the two species varied significantly from 2006 to 2007 $(\mathrm{P}<0.05)$. Indeed, ratio of $P$. paneum to $P$. roqueforti was 1.8 during the first year and turned 


\section{SURVEY OF FUNGAL DIVERSITY IN SILAGES SUPPLIED TO ...}

to 0.9 during the second year (Figure 1B). These two species belong to the $P$. roqueforti group, which was present in $78 \%$ and $67 \%$ of all the silos examined, respectively in 2006 and 2007.
Moreover, they co-occurred in $51 \%$ of the sampled silos. Penicillium carneum, as the third member of the $P$. roqueforti group, was not isolated from any sample.

Table 3: Fungi isolated from visually contaminated grass, maize and sugar beet pulp silages in Belgium between January and June in 2006 and 2007.

\begin{tabular}{|c|c|c|c|c|}
\hline \multirow[b]{2}{*}{ Genera and species } & \multicolumn{2}{|c|}{2006} & \multicolumn{2}{|c|}{2007} \\
\hline & $\begin{array}{c}\text { Nbr. of case of } \\
\text { isolation }\end{array}$ & $\begin{array}{c}\text { Percentage of } \\
\text { total isolates }\end{array}$ & $\begin{array}{c}\text { Nbr. of case } \\
\text { of isolation }\end{array}$ & $\begin{array}{c}\text { Percentage of } \\
\text { total isolates }\end{array}$ \\
\hline Alternaria alternate & 1 & 0.2 & 0 & 0.0 \\
\hline Aspergillus spp. & 12 & 2.4 & 3 & 0.6 \\
\hline Aspergillus oryzae & 2 & 0.4 & 0 & 0.0 \\
\hline Aspergillus niger & 6 & 1.2 & 0 & 0.0 \\
\hline Aspergillus tubingensis & 1 & 0.2 & 0 & 0.0 \\
\hline Unidentified Aspergillus & 3 & 0.6 & 3 & 0.6 \\
\hline Byssochlamys nivea & 10 & 2.0 & 2 & 0.4 \\
\hline Fusarium spp. & 6 & 1.2 & 5 & 1.1 \\
\hline Fusarium equiseti & 1 & 0.2 & 0 & 0.0 \\
\hline Fusarium verticillioides & 0 & 0.0 & 1 & 0.2 \\
\hline Fusarium oxysporum & 3 & 0.6 & 2 & 0.4 \\
\hline Fusarium redolens & 2 & 0.4 & 0 & 0.0 \\
\hline Unidentified Fusarium & 2 & 0.4 & 2 & 0.4 \\
\hline Geotrichum candidum & 8 & 1.6 & 11 & 2.4 \\
\hline Monascus ruber & 9 & 1.8 & 13 & 2.8 \\
\hline Monilia crassa & 0 & 0.0 & 2 & 0.4 \\
\hline Paecilomyces variotii & 6 & 1.2 & 3 & 0.6 \\
\hline Penicillium spp. & 254 & 50.6 & 243 & 52.4 \\
\hline Penicillium aurantiogriseum & 0 & 0.0 & 1 & 0.2 \\
\hline Penicillium brevicompactum & 0 & 0.0 & 1 & 0.2 \\
\hline Penicillium commune & 5 & 1.0 & 0 & 0.0 \\
\hline Penicillium citreonigrum & 7 & 1.4 & 0 & 0.0 \\
\hline Penicillium coprophilum & 1 & 0.2 & 0 & 0.0 \\
\hline Penicillium corylophilum & 2 & 0.4 & 2 & 0.4 \\
\hline Penicillium crustosum & 11 & 2.2 & 14 & 3.0 \\
\hline Penicillium expansum & 5 & 1.0 & 0 & 0.0 \\
\hline Penicillium islandicum & 3 & 0.6 & 1 & 0.2 \\
\hline Penicillium minioluteum & 11 & 2.2 & 2 & 0.4 \\
\hline Penicillium olsonii & 3 & 0.6 & 0 & 0.0 \\
\hline Penicillium palitans & 4 & 0.8 & 0 & 0.0 \\
\hline Penicillium paneum & 103 & 20.5 & 73 & 15.7 \\
\hline Penicillium polonicum & 1 & 0.2 & 0 & 0.0 \\
\hline Penicillium roqueforti & 58 & 11.6 & 82 & 17.7 \\
\hline Penicillium roseopurpureum & 2 & 0.4 & 0 & 0.0 \\
\hline Unidentified Penicillium & 38 & 7.6 & 67 & 14.4 \\
\hline Phoma spp. & 2 & 0.4 & 0 & 0.0 \\
\hline Trichoderma spp. & 70 & 13.9 & 29 & 6.3 \\
\hline Trichoderma asperellum & 2 & 0.4 & 0 & 0.0 \\
\hline Trichoderma atroviride & 23 & 4.6 & 10 & 2.2 \\
\hline Trichoderma harzianum & 7 & 1.4 & 0 & 0.0 \\
\hline Trichoderma viride & 1 & 0.2 & 1 & 0.2 \\
\hline Unidentified Trichoderma & 31 & 6.2 & 18 & 3.9 \\
\hline
\end{tabular}


TANGNI ET AL.

$\begin{array}{lcccc}\text { Mucor spp. } & 103 & 20.5 & 124 & 26.7 \\ \text { Verticillum spp. } & 4 & 0.8 & 0 & 0.0 \\ \text { Verticillium lamellicola } & 1 & 0.2 & 0 & 0.0 \\ \text { Verticillium lecanii } & 3 & 0.6 & 0 & 0.0 \\ \text { Unidentified } & 13 & 2.6 & 18 & 3.9 \\ \text { Yeast } & 4 & 0.8 & 11 & 2.4 \\ \text { Total } & \mathbf{5 0 2} & & \mathbf{4 6 4} & \end{array}$

Relative frequencies of isolation of fungi are illustrated in Figures 2, 3 and 4. The relative proportion of the prevalent fungal genera found in silages was independent of the nature of the crop ensiled $(\mathrm{P}=0.593)$ (Figure 2A) and varied significantly with the month of silo feed out $(\mathrm{P}<0.05)$ (Figure 2B). The same proportions of Penicillium, Trichoderma, Mucor and

A

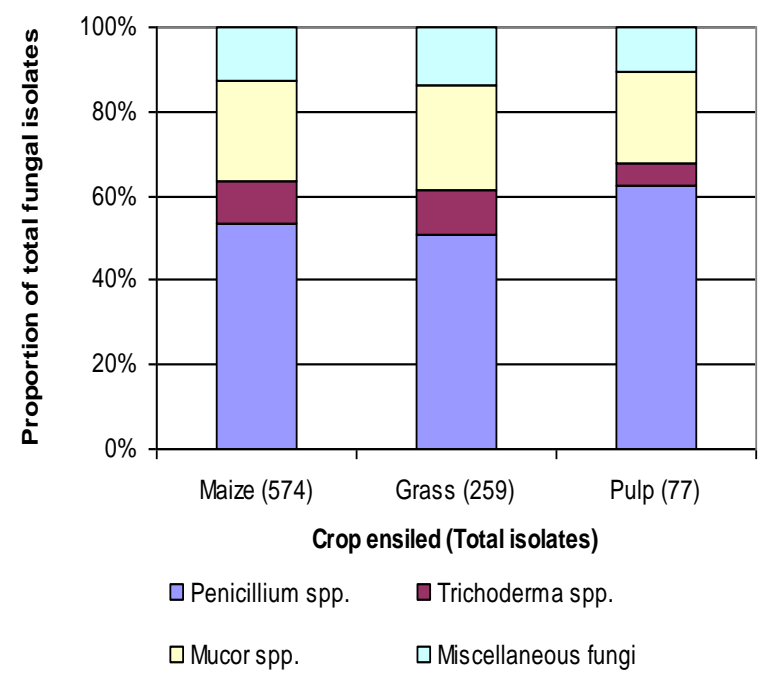

miscellaneous moulds (Aspergillus, Verticillium, Fusarium, etc.) were found in maize, grass and sugar beet pulp silages (Figure 2A). There were more mucorasceous molds during the spring (March-April) than during the winter and the summer, whereas the reverse trend was observed for the Penicillium incidence (Figure 2B).

$\overline{\mathrm{B}}$

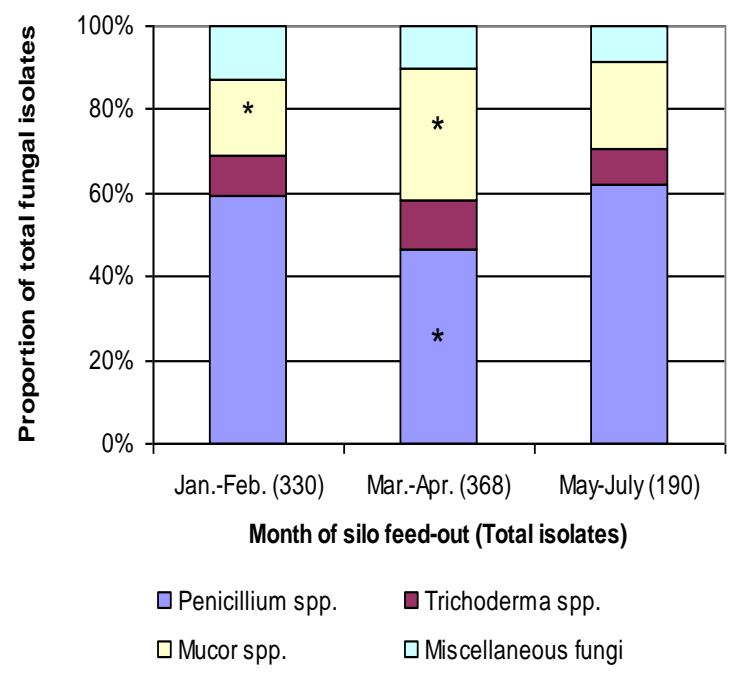

Fig. 2: Frequencies of fungal isolation in Belgian farm silages in 2006 and 2007 in relation to the crop ensiled (A) and the month of silo feed-out (B). Dependence of distribution of fungal species in categorical data was tested using the Chi square test at a level of $\mathrm{P}<0.05$. Asterisks over bars indicate major contributor categories in rejecting the null hypothesis according to the residuals chi square $>2.00$.

Over the two years of sampling, Penicillium species distribution was independent of the crop ensiled and the month of silo feed-out $(\mathrm{P}>0.05)$ (Figure 2). The ratio $P$. paneum to $P$. roqueforti was higher in 2006 than in 2007 (Figure 1B), but for each year considered separately this ratio was highly comparable between maize and grass silages (Figure 4) and throughout the whole feed out period of the silo (Figure 3). Only a few sugarbeet pulp silages could be visited and small expected frequencies inflate the chi-square test artificially (more than $25 \%$ of events in pulp silages had expected frequencies below 5). For this reason, the chi-square approximations were not considered for this forage crop. Nevertheless, in the few sugar beet pulp silages sampled, it has been observed that $P$. paneum was always isolated at a higher frequency than $P$. roqueforti (ratio $P$. paneum to $P$. roqueforti was 4.6 and 1.3, respectively for 2006 and 2007). 
A

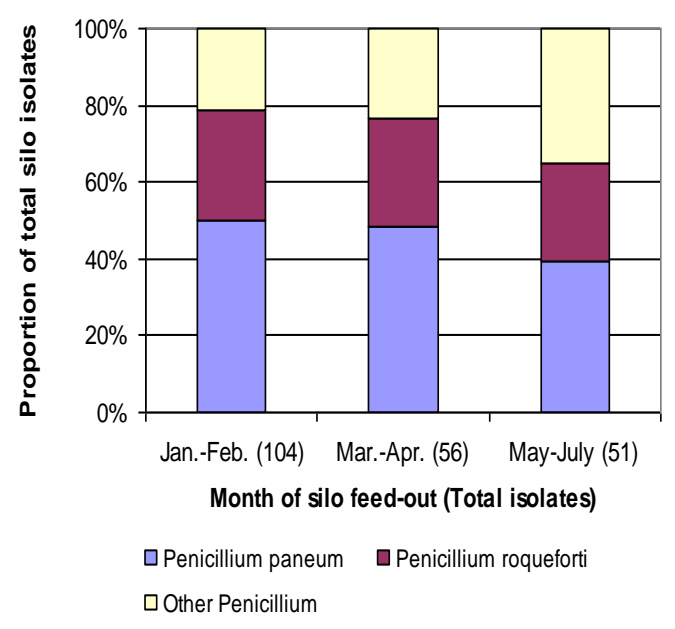

B

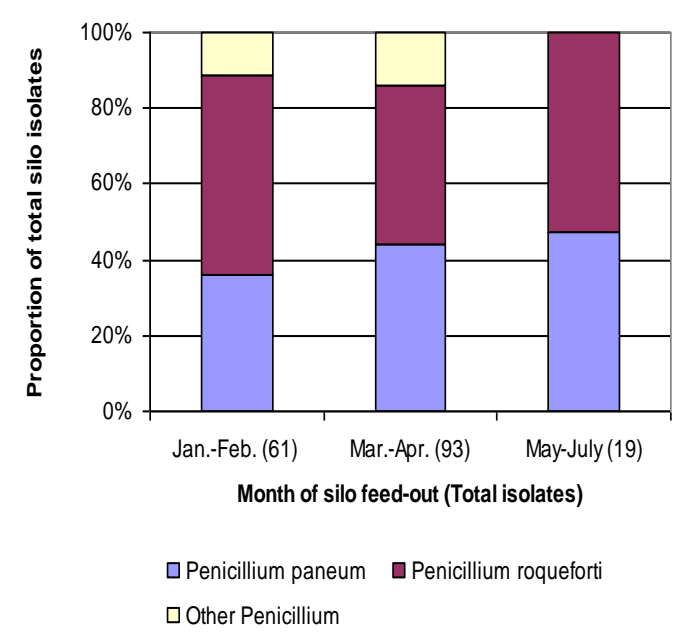

Fig. 3: Frequencies of Penicillium species isolated in Belgian farm silages in 2006 (A) and 2007 (B) in relation to the month of silo feed-out. Dependence of distribution of fungal species in categorical data was tested using the Chi square test at a level of $\mathrm{P}<0.05$.
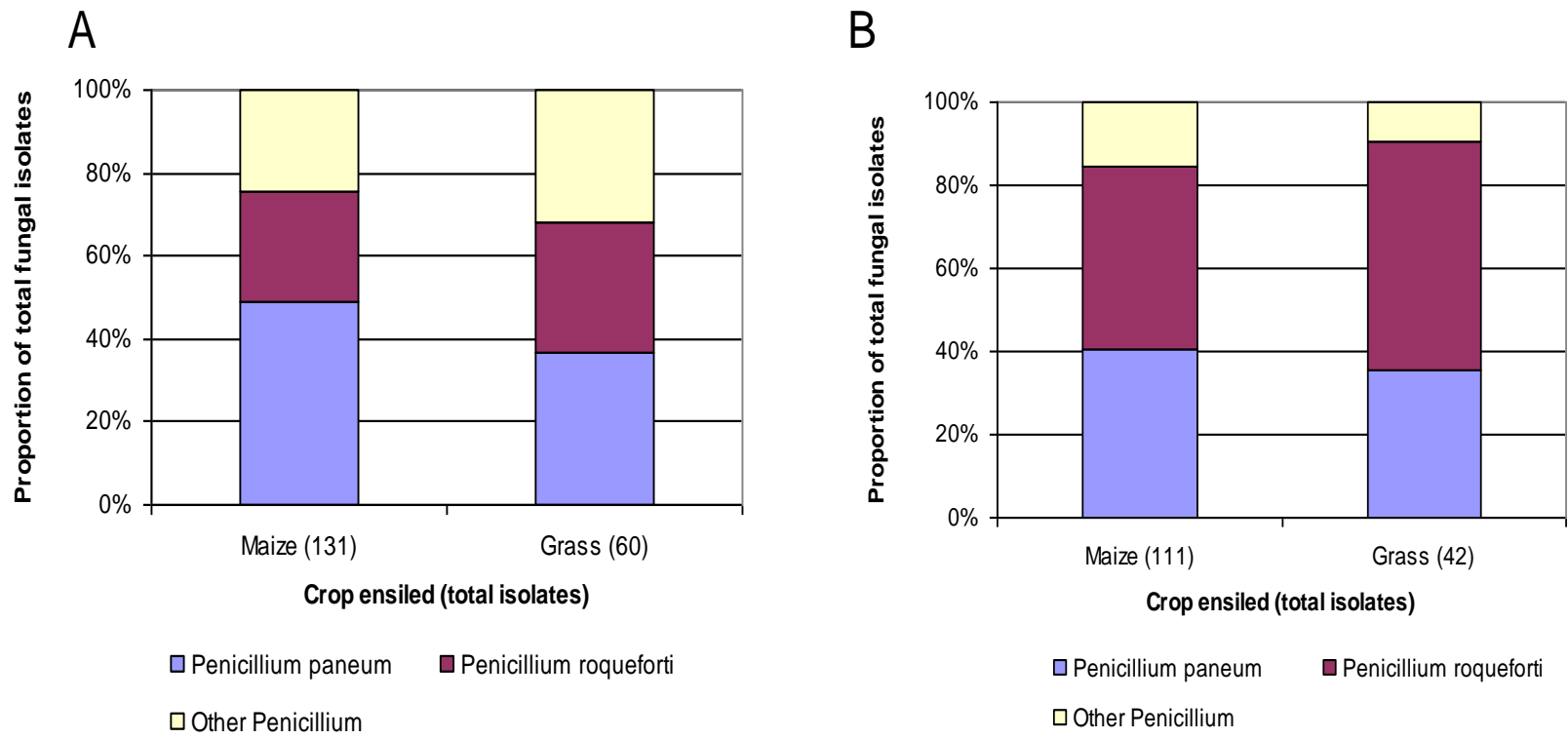

Fig. 4: Frequencies of Penicillium species isolation in farm Belgian silages in 2006 (A) and 2007 (B) in relation to the crop ensiled. Dependence of distribution of fungal species in categorical data was tested using the Chi square test at a level of $\mathrm{P}<0.05$.

\section{Relation farm Management and Ensiling Process}

Multiple influencing factors on silage quality at the different phases of the ensiling process collected with the questionnaire are summarized in Table 4. No general cause can be put forward as reason for mouldy silages, e.g. harvest time, chopping length, dimensions of silos, plastic layers, were generally all in the normal range. There was also no difference between a ground and a bunker silo. The use of additives was low for maize silages (only $7 \%$ ), while for pre-wilted grass additives were used in $53 \%$ of the sampled silos. Bacteria formulations, organic acids as well as salts were noted as used additives. 
TANGNI ET AL.

Table 4: Ensiling practices and characteristics of forage crops on farms surveyed in Belgium in 2006 and 2007.

\begin{tabular}{|c|c|c|c|}
\hline \multirow[b]{2}{*}{ Characteristics } & \multirow[b]{2}{*}{ Sub categories } & \multicolumn{2}{|c|}{ Proportion of farms visited for } \\
\hline & & $\begin{array}{l}\text { Maize silages } \\
(n=65)\end{array}$ & $\begin{array}{c}\text { Grass silages } \\
(n=47)\end{array}$ \\
\hline Crop rotation (in \%) & Yes & 81 & - \\
\hline \multirow[t]{5}{*}{ Previous crop (in \%) } & Wheat, & 33 & - \\
\hline & Potatoes, & 13 & - \\
\hline & Sugar beet, & 6 & - \\
\hline & Grass & 20 & - \\
\hline & Vegetables & 27 & - \\
\hline \multirow[t]{2}{*}{ Weather at harvest (in \%) } & Dry & 70 & 80 \\
\hline & Wet & 30 & 20 \\
\hline Additive applied (in \%) & Yes & 7. & 53 \\
\hline Age of the silo (weeks) at opening & Min-Max & $\begin{array}{c}\text { Between } 5 \\
\text { weeks and } 2 \\
\text { years }\end{array}$ & $\begin{array}{c}\text { Between } 5 \text { weeks } \\
\text { and a year }\end{array}$ \\
\hline \multirow[t]{4}{*}{ Harvest period (in \%) } & Spring & - & $100 \%$ \\
\hline & September & 24 & - \\
\hline & October & 67 & - \\
\hline & November & 9 & - \\
\hline Feeding rate $(\mathrm{cm} /$ day $)$ & & $\begin{array}{l}\text { Too less } \\
\text { information }\end{array}$ & $\begin{array}{c}\text { Too less } \\
\text { information }\end{array}$ \\
\hline \multirow[t]{3}{*}{ Type of silo (in \%) } & Bunker & 78 & 53 \\
\hline & Ground silo, & 22 & 32 \\
\hline & Bales & - & 15 \\
\hline \multirow[t]{4}{*}{ Height, length and width of the silo (m) } & $\operatorname{Min}-\max$ & & \\
\hline & Height & $1-3$ & $1-2,10$ \\
\hline & Length & $20-65$ & $20-30$ \\
\hline & Width & $5-12$ & $5-7,5$ \\
\hline Number of plastic film layers & 2 plastic layers & $100 \%$ & $100 \%$ \\
\hline Weight used on the plastic film layers & Tyres, ground & $100 \%$ Tyres & $100 \%$ Tyres \\
\hline Chopping length (mm) & Min.- Max & $8-15$ & 5- 8 \\
\hline Beginning of the silo contamination by & at opening & 51 & 62 \\
\hline \multirow[t]{4}{*}{ moulds after the opening of the silo (in \%) } & between $1-2$ weeks & 12 & 16 \\
\hline & between $2-3$ weeks & 12 & 12 \\
\hline & after 1 month & 7 & 10 \\
\hline & after several month & 7 & - \\
\hline $\begin{array}{l}\text { Anomalies in the animal husbandry } \\
\text { (health troubles, diminution of the feed } \\
\text { intake or the milk production, etc) }\end{array}$ & No & 100 & 100 \\
\hline
\end{tabular}

In general, most mould problems were already present at the opening of the silos (51 and $62 \%$ for maize and grass respectively). Another $24-28 \%$ of the mouldy spots became present in a period of 3 weeks after opening the silos, while $10-14 \%$ of the problems occurred later than a month after opening. This means that most of the problems were related to the conditions existing at the moment of installing the silos. However, in 2007 problems noted at opening of the silos were more in balance with problems that started after desiling. One could argue that a possible year effect (harvest conditions with effect on dry matter content e.g.) might be involved. The chemical parameters showed that in mouldy spots, the fermentation pattern has been disturbed due to fungal development: an elevated $\mathrm{pH}$ and reduced lactic acid levels were recorded in these parts (Table 5). 


\section{SURVEY OF FUNGAL DIVERSITY IN SILAGES SUPPLIED TO ...}

Table 5: Mean chemical characteristics of maize and grass silages sampled in 2006 - 2007 in Belgium.

\begin{tabular}{|c|c|c|c|c|c|}
\hline & \multicolumn{5}{|c|}{ Chemical parameters } \\
\hline & pH & $\mathbf{N H}_{3} / \mathbf{N}$ & Lactic acid $^{*}$ & Acetic acid ${ }^{*}$ & Butyric acid $^{*}$ \\
\hline Maize silages $(n=65)$ & & & & & \\
\hline Non-mouldy & $3.77^{\dagger}$ & 0.027 & $72.54^{\dagger}$ & 26.98 & $0.48^{\dagger}$ \\
\hline Mouldy & 5.13 & 0.034 & 61.78 & 34.78 & 2.41 \\
\hline Grass silages $(n=47)$ & & & & & \\
\hline Non-mouldy & $4.46^{\dagger}$ & 0.108 & $66.11^{\dagger}$ & 24.72 & 7.62 \\
\hline Mouldy & 5.37 & 0.087 & 51.55 & 33.34 & 11.22 \\
\hline
\end{tabular}

The increased presence of butyric acid points out the adverse fermentation conditions in the mouldy parts. Many reasons could be mentioned for a non-optimal fermentation by lactic acid bacteria: adverse condition of the starting material, such as too low or high dry matter content; poor natural bacterial flora; insufficient fermentable sugars; chopping length not in relation to dry matter content; soil contamination; certain parts of the silos are not tightly enough packed. Of course, these above reasons may be combined in different way.

\section{Discussion}

\section{Fungal Diversity}

Forty-seven species belonging to 13 genera were identified in maize, grass and sugar beet pulp silages in Belgium. It has been found that Penicillium (51.5\% of total isolates), Mucor (23.6\%), and Trichoderma (10.1\%) were the most prevalent moulds identified on the isolation media used. Other isolated moulds included Monascus sp. (4.6\%), Geotrichum sp. (2\%), Aspergillus spp. (1.5\%), Byssochlamys sp. (1.2\%) and Fusarium spp. (1.2\%). According to previous studies, Mucor and Penicillium species were also commonly isolated in silages in European countries (Netherlands, Germany and Ireland), or in North and South America (Nout et al., 1993, Auerbach et al., 1998; Tapia et al., 2005; O’Brien et al., 2007). In contrast, incidence of Trichoderma in Tapia et al. (2005) and O'Brien et al., (2007) surveys was low (between 0.02 and $0.5 \%$ of total isolates) compared to our results. The most frequently isolated Penicillium in silages were species from the $P$. roqueforti group, which was divided into three species, $P$. roqueforti, $P$. paneum and $P$. carneum, based on analysis of rDNA genes and chemotaxonomic profiles (Boysen et al., 2000). In agreement with other studies on the $P$. roqueforti group (Boysen et al., 2000; Garon et al., 2006; O'Brien et al., 2007; Mansfield and Kuldau, 2007; Richard et al., 2007) only $P$. roqueforti and $P$. paneum were isolated from silages. In the present study, Penicillium species encountered most frequently were $P$. roqueforti or $P$. paneum depending on the year of sampling and the type of forage crop. During the first year of sampling on grass and maize silages, the most frequently isolated Penicillium was $P$. paneum (ratio of $P$. paneum/P. roqueforti $=1.8$ ) while the opposite trend has been observed during the second year of sampling (ratio of $P$. paneum $/ P$. roqueforti $=0.9$ ).

For an accurate comprehension of this phenomenon, it would be interesting to follow the evolution of the $P$. roqueforti group populations in Belgium during other coming years. This trend might be confirmed with an increasing importance of $P$. roqueforti over $P$. paneum in silages or a fluctuating steady state of both populations might be observed. Since $P$. paneum were not frequently isolated in silages in the Netherlands, Germany and Irland, it would be also interesting to understand the reason of the apparent geographically limited higher frequency of isolation of $P$. paneum in Belgium as observed in our study. A possible explanation might be that isolates have been assigned to the $P$. roqueforti group, without making a distinction between $P$. roqueforti s.s. and $P$. paneum in these studies.

In sugar beet pulp silages, $P$. paneum was the predominant Penicillium species in both 2006 and 2007. These results contrast with several studies carried out in North America and Europe indicating 


\section{TANGNI ET AL.}

the predominance of $P$. roqueforti while the incidence of $P$. paneum was very low (O'Brien et al., 2007) or inexistent (Garon et al., 2006; Richard et al., 2007).

The isolation of $P$. roqueforti and $P$. paneum was expected because their ability to survive under silage conditions is well documented (Auerbach et al., 1998, Boysen et al., 2000, Mansfield and Kuldau, 2007). Members of the $P$. roqueforti group are unique in their high tolerance to low $\mathrm{pH}$, often in conjunction with organic acids, and to high $\mathrm{CO}_{2}$ and to low $\mathrm{O}_{2}$ content in the environment (Samson and Frisvad, 2004). Moreover, P. roqueforti has low temperature requirements and can grow at low water activity (75\%) (Bonner and Fergus, 1960; Samson and Frisvad, 2004). While the apparent inability of $P$. carneum to survive in silages is poorly understood, these ecological requirements of $P$. paneum and $P$. roqueforti could explain the prevalence of these strains in silages. On the other hand, other Penicillium species are not generalists and show a strong association with particular habitats (e.g. $P$. italicum and $P$. digitatum to citrus fruits). In parallel, considering other fungal contaminants in silages, the inability of Fusarium species to survive the low oxygen and low $\mathrm{pH}$ environment of silages has been reported (Mansfield and Kuldau, 2007) and can explain the low frequency of isolation of these strains in the silages sampled in this study.

The fungal development in silages is of particular concern. Fungal contaminations reduce nutritional value and silage palatability (DiCostanzo et al., 1995) and could result in the production of allergenic spores (Bui et al., 1994) and mycotoxins (Frisvad et al., 2006). The association between airborne fungi and symptoms of respiratory allergy and asthma is well established. More than 80 genera of fungi have been reported to be associated with respiratory tract allergy (Horner et al., 1995). Several studies carried out in dairy cattle sheds highlighted the moldy livestock feeds as source of airborne allergenic fungi (Bui et al., 1994, Adhikari et al., 2004). In this respect, silages sampled in our study could represent a risk factor for human and animal health: several species known to contain important allergens (Horner et al., 1995) were isolated such as Aspergillus spp. (1.5\%), Alternaria alternata $(0.2 \%)$ and Fusarium spp. (1.2\%).
Nevertheless, no cases of allergenic reactions on animals or humans were reported by farmers in our study. Since allergenic reactivity mainly depends on the composition and the load of airborne spores and the substantial antigen load exposed to individuals (Horner et al., 1995), the absence of allergenic reactions could be partly explained by the fact that the allergenic fungi isolated in our silages had a low incidence.

Silages surveyed in our study were an important source of potentially toxigenic fungi. Primary toxin producing moulds are Penicillium, Fusarium, and Aspergillus species (Yiannikouris and Jouany, 2002). These moulds represented 51.5, 1.2 and $1.5 \%$ of the total isolates in maize, grass and pulp silages, respectively.

These fungal species are producers of several known mycotoxins including aflatoxins, ochratoxins, patulin, deoxynivalenol, fumonisins, zearelenone, PR toxin and citrinin, and evidence is increasing that mycotoxins are regularly formed under ensiling conditions. Other moulds of importance in our study, such as Mucor (23.6\%) and Trichoderma species (10.1\%), should also be considered as potential mycotoxins producers in forages.

Citrinin, gliotoxin and deoxynivalenol have been detected in mature corn silages (Richard et al., 2007), roquefortine $C$ in wilted grass and wholecrop maize silages (Auerbach et al., 1998) and mycophenolic acid in grass and maize silages (Schneweis et al., 2000).

Most mycotoxins affect animals either by increasing disease incidence and reducing production efficiency. They can cause dermal toxicity, reproductive effects, carcinogenicity, neurotoxicity, teratogenicity, nephrotoxicity and hepatotoxicity. Additionally, mycotoxins may affect immune functions. Because of their prevalence in commonly ensiled forages in our study, and their potential for affecting dairy cattle production and health, special attention should be paid to the mycotoxin producers $P$. paneum and $P$. roqueforti. These two species were present on $78 \%$ and $67 \%$ of all silages examined, respectively in 2006 and 2007. Penicillium roqueforti can significantly produce roquefortine C, a mycotoxin with neurotoxic (paralytic) properties. It can also produce PR toxins which have nephrotoxic and 


\section{SURVEY OF FUNGAL DIVERSITY IN SILAGES SUPPLIED TO ...}

hepatotoxic effects on animals. Penicillium paneum would also be of concern because of its ability to produce patulin, a carcinogenic and hemorrhaging mycotoxin. Other mycotoxins such as aflatoxin or zearelenone can also be formed in forage prior to ensilage and resist to the ensiling process (Garon et al., 2006).

A recent study also showed that the Penicillium mycotoxins patulin, mycophenolic acid, cyclopiazonic acid and roquefortine $\mathrm{C}$ can be found in freshly harvested material, contradicting the belief that Penicillium toxin formation occurs during mature stage of crop and storage (Mansfield et al., 2008). Taking into account mouldy and nonmouldy fractions of some samples involved in the present study, Tangni et al. (2013b) analyzed the roquefortine $\mathrm{C}$, mycophenolic acid, citrinin and ochratoxin A contents in these samples and concluded that the absence of visible mouldy parts does not guarantee absence of these mycotoxins in feedstuffs.

\section{Relationship between Fungal Species} Composition in Silages and Agronomic Practices and Fermentation Characteristics

Various environmental factors and silage characteristics (e.g. moisture content, pH, acid temperature and gas composition) were likely to influence the species composition of the fungal population.

Bonner and Fergus (1960) have found on maize silages at lab scale that 10 fungal strains exhibited considerable differences in growth over a 30-days period at the two temperatures tested $\left(25\right.$ and $\left.37^{\circ} \mathrm{C}\right)$ at six relative humidity levels (ranging from 65 to $100 \%)$. Additionally, silage production and management practices can favor fungal development and species composition of the fungal population during forage storage and feed out. O'Brien et al., (2007) observed that bale handling and storage practices on farms can greatly influence both the number and types of fungal propagules within silage bales: $P$. roqueforti was positively correlated to month of bale feed-out and to bale age.

In the present study, neither the crop rotation, the date and weather at harvest, the use of additives, the feeding rate, the type and dimension of silo, the covering used or the forage chopping length at ensiling could be significantly correlated to the fungal species composition isolated in farm silages. There were also no significant relationships between the chemo-fermentative parameters tested (dry matter, $\mathrm{pH}, \mathrm{NH} 3$ content concentration of lactic, acetic and butyric acids) and the fungal species composition in silages. These findings suggest that the prevalent fungi that were able to survive in silages were tolerant of the wide ranges of conditions found in the farm silages sampled in this study (different kind of crop forages, wide range of $\mathrm{pH}$ and dry matter content, etc.).

For instance, contrasting with other Penicillium species showing a strong association with particular habitats (e.g. P. italicum and $P$. digitatum to citrus fruits), members of the $P$. roqueforti group are unique in their ability to survive in wide range of $\mathrm{pH}$, water activity and $\mathrm{O}_{2}$ content (Bonner and Fergus, 1960; Samson and Frisvad, 2004). It has been shown that $P$. roqueforti and $P$. paneum grew correctly between $\mathrm{pH} 3$ and $\mathrm{pH} 7$ with an optimum between pH 4 and pH 5 (Vivier et al., 1992), while silage $\mathrm{pH}$ in our study ranged from 3.12 to 8.18 . The ability of these strains to survive in the $\mathrm{pH}$ environment of all the silages sampled, in combination with their tolerance to low oxygen content and low water activity as commonly found in silages, could explain that no significant relationships have been found between composition of Penicillium population in silages and agronomic practices and fermentation characteristics.

Silos are not a homogenous environment showing that zones with more and less O2, differences in $\mathrm{pH}$, fermentation rate exist. The prevalent fungi were tolerant of the wide ranges of conditions found in the farm silages with year-toyear variations. As stated by Wambacq et al., (2016), the most reliable and consistent strategy for controlling mycotoxins is exploitation of cultivars with good resistance and identification of specific markers for selection and development of cultivars with good resistance to mycotoxin contamination. Moreover, the use of good silage making practices remains fundamental to prevent deterioration and the feed out phase must be considered, as penetration of the oxygen into mass triggers an onset of mould growth. For safety purposes, evaluation of fungal development that leads to the estimation of viable fungal population is valuable. 
TANGNI ET AL.

\section{Acknowledgements}

The financial support (Contract C3/00/22) of the Belgian Federal Public Planning Service (Science Policy) is acknowledged here. A thanks is also due to the farmers for their kind participation in sampling of their silages.

\section{References}

Adhikari A, Sen MM, Gupta-Bhattacharya S, Chanda S (2004). Volumetric assessment of airborne fungi in two sections of rural indoor dairy cattle shed. Envir. Int., 29: 1071-1078.

Auerbach H, Oldenburg EL, Weissbach F (1998). Incidence of Penicillium roqueforti and roquefortine $\mathrm{C}$ in silages. $\mathrm{J}$. Sci. Food Agri., 76: 565-572.

Bonner RD, Fergus CL (1960). The influence of temperature and relative humidity on growth and survival of silage fungi. Mycologia. 52: 642-647.

Boysen SR, Jacobsson FG, Schnurer J (2000). Molecular identification of species from the Penicillium roqueforti group associated with spoiled animal feed. Appl. Env. Microbiol., 66: 1523-1526.

Bui AM, Germaud P, Normand de la Tranchade, Touranchet A (1994). Ensilage et aspergillose broncho-pulmonaire allergique. Arch. Mal. Prof. Med., 55: 335-337.

Cheli F, Campagnoli A, Dell'Orto V (2013). Fungal populations and mycotoxins in silages: From occurrence to analysis. Anim. Feed Sci. Technol., 183: 1-16.

D’Mello JPF, Placinta CM, Macdonald AMC (1999). Fusarium mycotoxins: A review of global implications for animal, health, welfare and productivity. Anim. Feed Sci. Technol., 80(3-4): 183-205.

DiCostanzo A, Johnston L, Felice L, Murphy M (1995). Effect of moulds on nutrient content of feeds reviewed. Feedstuffs 67: 17-54.

Frisvad JC, Thrane U, Samson RA, Pitt JI (2006). Important mycotoxins and the fungi which produce them. Adv. Exp. Med. Biol., 571: 3-31.

Garon D, Richard E, Sage L, Bouchart V, Pottier D, Lebailly $P$ (2006). Mycoflora and multimycotoxin detection in corn silage: experimental study. J. Agri. Food Chem., 54: 3479-3484.

Horner WE, Helbling A, Salvaggio JE, Lehrer SB (1995). Fungal allergens. Clin. Microbiol. Rev., 8: 161-179.

Leps J, Smilauer P (1999). Multivariate analysis of ecological data. Faculty of Biological Sciences. University of South Bohemia.

Mansfield MA, Jones AD, Kuldau GA (2008). Contamination of fresh and ensiled maize by multiple Penicillium mycotoxins. Phytopathol., 98: 330-336.

Mansfield MA, Kuldau GA (2007). Microbiological and molecular determination of mycobiota in fresh and ensiled maize silage. Mycologia. 99: 269-278.

Nout MJR, Bouwmeester HM, Haaksma J, van Dijk H (1993). Fungal growth in silages of sugar beet press pulp and maize. J. Agri. Sci., 121: 323-236.
O’Brien M, O'Kiely P, Forristal PD, Fuller HT (2007). Visible fungal growth on baled grass silage during the winter feeding season in Ireland and silage characteristics associated with occurrence of fungi. Anim. Feed Sci. Technol., 139: 234-256.

O’Brien M, O'Kiely P, Forristal PD, Fuller HT (2008). Fungal contamination of big-bale grass silage on Irish farms: predominant mould and yeast species and features of bales and silage. Grass Forage Sci., 63: 121-137.

Ohmomo S, Tanaka O, Kitamoto H (1993) Analysis of organic acids in silage by high-performance liquid chromatography. Bull Natl. Grassl Res. Inst., 48: 51-56.

Richard E, Heutte N, Sage L, Pottier D, Bouchart V, Lebailly P, Garon D (2007). Toxigenic fungi and mycotoxins in mature corn silage. Food Chem. Toxicol., 45: 24202425.

Samson RA, Frisvad JC (2004). Penicillium subgenus Penicillium: new taxonomic schemes, mycotoxins and other extrolites. Stud. Mycol., 49: 1-266.

Samson RA, Hoekstra ES, Frisvad JC, Filtenborg O (2002). Introduction to food- and airborne fungi. Centralbureau voor Schimmelcultures, Utrecht, Netherlands. pp. 389.

Schneweis I, Meyer K, Hörmansdorfer S, Bauer J (2000). Mycophenolic acid in silage. Appl. Environ. Microbiol., 66: 3639-3641.

Scudamore KA, Livesy CT (1998). Occurrence and significance of mycotoxins in forage crops and silage: a review. J. Sci. Food Agri., 77: 1-17.

Tangni EK, Pussemier L, Bastiaanse H, Haesaert G, Foucart G, van Hove F (2013b). Presence of Mycophenolic Acid, Roquefortine C, Citrinin and Ochratoxin A in Maize and Grass Silages Supplied to Dairy Cattle in Belgium. J. Anim. Sci. Adv., 3(12): 598-612.

Tangni EK, Pussemier L, Van Hove F (2013a). Mycotoxin Contaminating Maize and Grass Silages for Dairy Cattle Feeding: Current State and Challenges. J. Anim. Sci. Adv., 3(10): 492-511.

Tapia MO, Stern MD, Soraci AL, Meronuck R, Olson W, Gold S, Koski-Hulbert RL, Murphy MJ (2005). Patulinproducing molds in corn silage and high moisture corn and effects of patulin on fermentation by ruminal microbes in continuous culture. Anim. Feed Sci. Technol., 119: 247-258.

Vivier D, Rivemale M, Reverbel JP, Ratomahenina R, Galzy P (1992). Some observations on the physiology of Penicillium roqueforti Thom and Penicillium cyclopium Westling. Lait. 72: 277-283.

Wambacq E, Vanhoutte I, Audenaert K, de Gelder L, Haesaert $G$ (2016). Occurrence, prevention and remediation of toxigenic fungi and mycotoxins in silage: A review. J. Sci. Food Agri., 96(7): 2284-2302. 